\title{
OVERCOMING SOCIAL ISOLATION WITH DIGITAL TECHNOLOGIES AMONG AGEING POPULATIONS DURING COVID-19
}

\author{
Ieva Reine \\ Riga Stradins University, Statistics Unit, Latvia \\ Andrejs Ivanovs \\ Riga Stradins University, Statistics Unit, Latvia \\ Inta Mierina \\ University of Latvia, Institute of Philosophy and Sociology, Latvia \\ Ilona Gehtmane-Hofmane \\ Riga Stradins University, Public Health Institute, Latvia \\ Ilze Koroleva \\ University of Latvia, Institute of Philosophy and Sociology, Latvia
}

\begin{abstract}
During Covid-19 social isolation has become more common worldwide, however, some groups, especially elderly people, might have experienced dramatically limited communication due to the lack of skills and access to digital technologies. In this paper, we examined if education was associated with the use of digital technologies to maintain contacts with a family, friends, other social networks and services. The survey was conducted in JuneAugust 2020 by doing 1089 computer-assisted telephone interviews. The questions examined how people aged 50 years and older coped with socioeconomic and health-related impact of COVID-19.

We used logistic regression analysis to study the association between the use of digital technologies and the level of education by gender and age. The higher the education was, the more it strongly associated with the use of digital technologies (OR 5.85; 95\% CI 3.78-9.03). As expected, age was a strong explanatory factor, however, we did not find consistent age and gender differences. Among those who used digital technologies, analyses showed that overcoming social isolation was related to the education level. The conclusion of the study is that education has inevitable impact on the use of digital technologies and social contacts, however high education level is not crucial for the acquisition of information. It seems that digital technologies are important tools to prevent social isolation and are related to education that includes digital access and competencies.
\end{abstract}

Keywords: education level, gender, Latvia, network, Survey of Health, Ageing, and Retirement (SHARE). 
Reine et al., 2021. Overcoming Social Isolation with Digital Technologies Among Ageing Populations During Covid-19

\section{Introduction}

As coronavirus cases raise again, solutions for older adults to find ways to overcome social isolation and loneliness has an inevitable importance. COVID19 as a pandemic has remarkably diminished possibilities for the older people to engage in meaningful, productive activities with others that are based on physical contacts and are strong prerequisites of healthy ageing (National Institute of Ageing, 2019). Activities that normally help to maintain wellbeing are limited due to social isolation because of government recommendations and restrictions, and also fear knowing that the infection can have life-threatening complications (Centers for Disease Control and Prevention, 2020).

Social isolation and loneliness are associated with higher risks for a variety of physical and mental conditions: high blood pressure, heart disease, obesity, a weakened immune system, anxiety, depression, cognitive decline, Alzheimer's disease, and even death (Cacioppo JT. \& Cacioppo S., 2014; 2018). Unexpected events due to the death of a spouse or partner, separation from friends or family, retirement, etc. pose people at a particular risk of loneliness. COVID-19 has escalated those risks as many elderly people find themselves in a socially distanced situation due to the lack of physical contacts.

The COVID-19 outbreak has accelerated a shift to the use of digital technologies for almost everyone. Schoolchildren of today who have been surrounded by digital technology since their birth have also been given particular support to engage in online education, as well as in many cases provided with necessary devices. Older adults, especially those outside the labor market, on the contrary, have been invisible as regards assistance to use digital technologies. Older adults tend to be excluded from digital services because they do not use the internet to the same extent as younger generations, lack necessary devices and network connectivity, or are inexperienced using the technology (Seifert, Cotton, \& Xie, 2020). Thus, they struggle with the double burden of social and digital exclusion. For this reason, it seems more important than ever to plan models and/or strategies allowing the older adult population to acquire and enhance digital competencies more easily.

COVID-19 has forced many more people to use the internet in new ways compared to the time before the outbreak. The ability to work from home, stay connected with a family or friends, socialize, shop, access healthcare, and keep physically active have all - to varying degrees - been dependent on the ability to get online, even for the older ones (Martínez-Alcalá et al., 2018). Limited possibilities to use internet also influences whether older adults can access online services and content, such as health information, digital social events, social networking, and online shopping (Seifert, Cotton, \& Xie, 2020). Many 
activities, information and services have moved exclusively online without offering offline alternatives or with offline alternatives being limited or restricted. This has placed those without digital access and competencies at even greater risk of missing out than before the outbreak (Centre for Ageing Better, 2020). Not only the situation during the COVID-19 pandemic but also the overall decentralization of services has led to expectations that an increasing number of older adults will be able to use Internet-based services-health, education, finance and others (Martínez-Alcalá et al., 2018).

The aim of the study was to examine, if education was associated with the use of digital technologies to maintain contacts with a family, friends, other social networks and services and put forward policy recommendations to promote digital engagement among older persons.

\section{Material and Methods}

Quantitative data collected as part of a special module developed in Latvia adjacent to the 8th wave of the Survey of Health, Ageing and Retirement in Europe (SHARE) was used in the study. A special extra module within the ongoing wave was developed and implemented in Latvia after the first wave of the Covid-19 pandemic. The survey was conducted using paper assisted telephone interviews (PATI). The target population of the SHARE survey consisted of permanent residents of the European countries over the age of 50 and their spouses. The survey was conducted in June-August 2020 by doing 1089 computer-assisted telephone interviews. The questions examined how people over 50 years of age coped with socioeconomic and health-related impact of COVID-19.

The sample consisted of SHARE longitudinal panel participants, SHARE wave 7 respondents, as well as those respondents in the wave 8 update who were interviewed before the start of the COVID-19 pandemic. The sample size used in this study consists of 976 valid cases.

In order to ensure the representativeness of the data and a balanced composition of respondents according to the general population of Latvia, the data were subjected to a weighting procedure by gender and age (Central Statistical Bureau data).

The data was analyzed in IBM SPSS 26 using bivariate and multivariate statistics. For descriptive analyses, chi-square $\left(\chi^{2}\right)$ tests and t-tests were used to compare differences between men and women. Secondly, a logistic regression model was used for analysis of the population to estimate the unadjusted (Model 1) and adjusted (Model 2) odds ratios (ORs) and 95\% confidence 
Reine et al., 2021. Overcoming Social Isolation with Digital Technologies Among Ageing Populations During Covid-19

intervals (95\% CI) of the correlation between the use of digital technologies and three levels of education - basic (reference), secondary and higher. In these regression analyses, ORs were adjusted for age and gender.

\section{Research Results}

Basic sociodemographic characteristics of the 976 respondents aged 50 and above are detailed in Table 1 . The mean age of the respondents was 66.5 years; women were slightly older than men. There were significant statistical differences in the education level between men and women $(\mathrm{p}<0.001)$. Among the respondents, the highest proportion (44.8\%) had secondary education, whereof almost half of all participating women. A total of 634 persons (65\%) used digital technologies, mostly to communicate with a family and friends $(91.2 \%)$, and women were more prone to do so compared to men $(\mathrm{p}<0.05)$. However, men used digital technologies to acquire necessary information to a larger extent than women.

Table 1 Characteristics of the Respondents Aged $<50$ years (mean, SD, N, \%)

\begin{tabular}{|l|l|l|l|l|l|l|l|}
\hline Group & \multicolumn{2}{l|l}{$\begin{array}{l}\text { All } \\
(\mathrm{N}=976)\end{array}$} & \multicolumn{2}{l|l}{$\begin{array}{l}\text { Men } \\
(\mathrm{N}=385)\end{array}$} & \multicolumn{2}{l|l}{$\begin{array}{l}\text { Women } \\
(\mathrm{N}=591)\end{array}$} & $\begin{array}{l}\text { P } \\
\text { men/women }\end{array}$ \\
\hline Age (mean, SD) & 66.5 & 11.5 & 64.3 & 9.46 & 67.5 & 10.9 & $\mathbf{0 . 0 8 1}$ \\
\hline Education level (N, \%) & & & & & & & $<\mathbf{0 . 0 0 1}$ \\
\hline Basic & 224 & 24.0 & 67 & 19.3 & 157 & 28.2 & \\
\hline Secondary & 405 & 44.8 & 186 & 53.6 & 218 & 39.2 & \\
\hline Higher & 275 & 30.4 & 94 & 27.1 & 181 & 32.6 & \\
\hline Used digital technologies (N, \%) & & & & & & & 0.815 \\
\hline Yes & 634 & 65.0 & 248 & 64.6 & 386 & 65.3 & \\
\hline No technologies in & 342 & 35.0 & 136 & 35.4 & 205 & 34.7 & \\
\hline $\begin{array}{l}\text { Used digital } \\
\text { order to (N, \%) }\end{array}$ & & & & & & & \\
\hline $\begin{array}{l}\text { Communicate with a family and } \\
\text { friends }\end{array}$ & 578 & 91.2 & 219 & 88.3 & 359 & 93.0 & $\mathbf{0 . 0 4 2}$ \\
\hline Receive healthcare services & 224 & 35.2 & 82 & 32.9 & 142 & 36.8 & 0.321 \\
\hline Acquire necessary information & 562 & 89.8 & 228 & 91.9 & 334 & 88.8 & $\mathbf{0 . 0 4 4}$ \\
\hline Make internet purchases & 113 & 17.9 & 41 & 16.5 & 72 & 18.7 & 0.487 \\
\hline
\end{tabular}

Bivariate logistic regression (Table 2, Model 1) was performed in order to assess the association between the use of digital technologies, the different purposes they were used for, age, gender and education. Significant associations were found for women as regards communication with friends and family, and 
for men as regards acquisition of information. Older age was also associated with acquisition of information as well as purchases on internet.

Table 2 Logistic Regression for the Use of Digital Technologies, Using Digital Technologies for Different Purposes and Education Levels. Model 1: bivariate logistic regression; Model 2: adjusted for age and gender, OR, 95\% CI.*

\begin{tabular}{|c|c|c|c|c|c|}
\hline Variable & $\begin{array}{l}\text { Used digital } \\
\text { technologies }\end{array}$ & $\begin{array}{l}\text { Communicate } \\
\text { with a family } \\
\text { and friends }\end{array}$ & $\begin{array}{l}\text { Receive } \\
\text { healthcare } \\
\text { services }\end{array}$ & $\begin{array}{l}\text { Acquire } \\
\text { necessary } \\
\text { information }\end{array}$ & $\begin{array}{l}\text { Make } \\
\text { internet } \\
\text { purchases }\end{array}$ \\
\hline & $\begin{array}{l}\text { OR } \\
(95 \% \mathrm{CI})\end{array}$ & $\begin{array}{l}\text { OR } \\
(95 \% \mathrm{CI})\end{array}$ & $\begin{array}{l}\text { OR } \\
(95 \% \mathrm{CI})\end{array}$ & $\begin{array}{l}\text { OR } \\
(95 \% \mathrm{CI})\end{array}$ & $\begin{array}{l}\text { OR } \\
(95 \% \mathrm{CI})\end{array}$ \\
\hline \multicolumn{6}{|l|}{$\begin{array}{l}\text { MODEL 1 } \\
\text { (unadjusted) }\end{array}$} \\
\hline $\begin{array}{l}\text { Gender } \\
\text { (Men=reference) }\end{array}$ & $\begin{array}{l}0.97 \\
(0.74-1.27)\end{array}$ & $\begin{array}{l}0.55 \\
(0.32-0.96)\end{array}$ & $\begin{array}{l}0.84 \\
(0.60-1.18)\end{array}$ & $\begin{array}{l}1.78 \\
(1.03-3.07)\end{array}$ & $\begin{array}{l}0.86 \\
(0.56-1.31)\end{array}$ \\
\hline Age & $\begin{array}{l}1.10 \\
(1.08-1.11)\end{array}$ & $\begin{array}{l}1.00 \\
(0.97-1.03)\end{array}$ & $\begin{array}{l}0.99 \\
(0.97-1.01)\end{array}$ & $\begin{array}{l}1.07 \\
(1.04-1.10)\end{array}$ & $\begin{array}{l}1.04 \\
(1.01-1.07)\end{array}$ \\
\hline \multicolumn{6}{|l|}{ Education } \\
\hline $\begin{array}{l}\text { Basic } \\
\text { (reference) }\end{array}$ & $\begin{array}{l}1 \\
-\end{array}$ & $\begin{array}{l}1 \\
-\end{array}$ & $\begin{array}{l}1 \\
-\end{array}$ & $\begin{array}{l}1 \\
-\end{array}$ & $\begin{array}{l}1 \\
-\end{array}$ \\
\hline Secondary & $\begin{array}{l}6.73 \\
(4.35-10.4)\end{array}$ & $\begin{array}{l}2.64 \\
(1.08-6.43)\end{array}$ & $\begin{array}{l}1.88 \\
(1.15-3.05)\end{array}$ & $\begin{array}{l}4.48 \\
(2.29-8.76)\end{array}$ & $\begin{array}{l}2.99 \\
(1.56-8.72)\end{array}$ \\
\hline Higher & $\begin{array}{l}4.86 \\
(3.26-7.24)\end{array}$ & $\begin{array}{l}3.02 \\
(1.41-6.45)\end{array}$ & $\begin{array}{l}1.53 \\
(1.05-2.22)\end{array}$ & $\begin{array}{l}1.40 \\
(0.71-2.77)\end{array}$ & $\begin{array}{l}3.35 \\
(2.01-5.62)\end{array}$ \\
\hline \multicolumn{6}{|l|}{$\begin{array}{l}\text { MODEL } 2 \\
\text { (adjusted) }\end{array}$} \\
\hline $\begin{array}{l}\text { Gender } \\
\text { (Men=reference) }\end{array}$ & $\begin{array}{l}0.70 \\
(0.50-0.97)\end{array}$ & $\begin{array}{l}0.57 \\
(0.31-1.04)\end{array}$ & $\begin{array}{l}0.87 \\
(0.61- \\
1.24)\end{array}$ & $\begin{array}{l}1.55 \\
(0.85-2.81)\end{array}$ & $\begin{array}{l}0.88 \\
(0.56-1.41)\end{array}$ \\
\hline Age & $\begin{array}{l}0.91 \\
(0.90-0.93)\end{array}$ & $\begin{array}{l}1.01 \\
(0.97-1.04)\end{array}$ & $\begin{array}{l}0.99 \\
(0.97-1.01)\end{array}$ & $\begin{array}{l}1.06 \\
(1.03-1.09)\end{array}$ & $\begin{array}{l}1.05 \\
(1.02-1.08)\end{array}$ \\
\hline \multicolumn{6}{|l|}{ Education } \\
\hline $\begin{array}{l}\text { Basic } \\
\text { (reference) }\end{array}$ & $\begin{array}{l}1 \\
- \\
\end{array}$ & $\begin{array}{l}1 \\
- \\
\end{array}$ & $\begin{array}{l}1 \\
- \\
\end{array}$ & $\begin{array}{l}1 \\
- \\
\end{array}$ & $\begin{array}{l}1 \\
- \\
\end{array}$ \\
\hline Secondary & $\begin{array}{l}5.02 \\
3.13-8.05\end{array}$ & $\begin{array}{l}2.62 \\
(1.06-6.49)\end{array}$ & $\begin{array}{l}1.98 \\
(1.21-3.26)\end{array}$ & $\begin{array}{l}3.49 \\
(1.74-9.95)\end{array}$ & $\begin{array}{l}2.58 \\
(1.33-4.99)\end{array}$ \\
\hline Higher & $\begin{array}{l}5.85 \\
3.78-9.03\end{array}$ & $\begin{array}{l}2.88 \\
(1.34-6.17)\end{array}$ & $\begin{array}{l}1.50 \\
(1.03-2.19)\end{array}$ & $\begin{array}{l}1.52 \\
(0.76-3.02)\end{array}$ & $\begin{array}{l}3.38 \\
(2.02-5.66)\end{array}$ \\
\hline
\end{tabular}

*OR $=$ Odds Ratio $; 95 \% \mathrm{CI}=95 \%$ Confidence Interval; $\mathrm{p}$ value significant at $<0.001$ level

In Model 2 (Table 2), the associations between the use of digital technologies and education level remained strong even after adjustment for age 
Reine et al., 2021. Overcoming Social Isolation with Digital Technologies Among Ageing Populations During Covid-19

and gender. Those with higher education have higher odds to use digital technologies than those with basic education.

\section{Discussion}

Strong associations were found between higher education levels and the use of digital technologies, even after adjusting for age and gender.

The association between older age and use of digital technologies during Covid-19 might be related to the advised restrictions of meeting other people and to be in contact remotely instead, however, those with lower education might have had it more difficult to catch up with the new challenges.

It can be concluded that those with secondary and higher education might have a lower risk of social isolation due to a higher use of digital technologies. Like other studies show, lack of skills, affordability, cognitive problems etc. are plausible explanations (Seifert, Cotton, \& Xie, 2020). As adjustment for age and gender did not have a considerable impact on the associations between the use of digital technologies and education, we can conclude that communication with a family and friends is important to overcome social isolation for most respondents, even though it is easier for those with higher education levels.

However, the most vulnerable groups, including older persons with low education, seem to face double burden of social exclusion. Our results are in line with other studies indicating less access to online services and content, such as health information and services, social networking, and online purchases (Seifert, Cotton, \& Xie, 2020).

Our study suggests the need to develop mechanisms preventing social isolation regardless of digital access and competencies. On the other hand, putting forward models and/or strategies is also important to ensure that the older adult population has prerequisites to acquire and enhance digital competencies more easily (Martínez-Alcalá et al., 2018). Older adults with lower education might think that digital technologies are difficult to use and some believe that they are not capable of learning to use them. The lack of exposure to the internet over the life course can also affect how relevant or valuable people perceive online access to be (Centre for Ageing Better, 2020). Many people prefer offline alternatives and do not identify themselves as internet users. Therefore, it has been suggested in previous studies before the COVID-19 outbreak that new ways to introduce digital technologies to currently excluded potential users should be examined, and also to improve the design of digital products so that they are easy to use and easy to learn, which can facilitate adoption by all types of users (Martínez-Alcalá et al., 2018). 
As other studies show (Hodge et al., 2017; Tam, 2018), learning can be carried out under many and varied conditions, not only in classrooms. Older people have accumulated a countless number of hours of informal learning; therefore, it is not enough to provide older people access to existing services (Martínez-Alcalá et al., 2018). It is also important to create educational environments which recognize and support all types of learning and all types of previous experience (Hodge et al., 2017; Tam, 2018), so that they would support even those with lower education. Martínez-Alcalá et al. (2018) suggest the educational model toward digital literacy of the elderly including Usefulness of Learning, Cooperativeness and collaboration, Fostering social inclusion and Promoting autonomy. Thus, the knowledge acquired should decrease the double burden of social isolation among older adults and give them a possibility of expanding communication channels through the internet with their relatives and friends, either close or distant.

Digital inclusion would ensure people with different education levels to use the internet and online technologies to meet their needs. As a report of Centre for Ageing Better (2020) suggests, the prerequisites include: (1) infrastructure being able to afford or have access to a device (whether a mobile phone, tablet or computer), as well as being able to afford or have access to the internet through broadband, Wi-Fi or mobile data; (2) skills - having the ability, confidence and digital skills to use digital devices and the internet; (3) accessibility - having access to services that are designed to meet users' needs, including for individuals with disabilities that require assistive technology to get online. These suggestions are in line with our current results and a recent report the researcher group of this project submitted to the Ministry of Welfare of Latvia (submitted) where financial obstacles as well as cognitive problems were discussed and suggested for the future policy development. As other previously mentioned studies also have suggested, government and service providers should invest in schemes to support those who are digitally excluded to get online.

\section{Acknowledgements}

The study was performed within the project "Impact of Covid-19 on ageing populations in Latvia: recommendations for mitigation health and social effects and preparedness for potential crises in the future" in the framework of VPPCOVID-2020/1-0011 "Impact of COVID-19 on health care system and public health in Latvia; ways in preparing health sector for future epidemics”. 
Reine et al., 2021. Overcoming Social Isolation with Digital Technologies Among Ageing Populations During Covid-19

\section{References}

Cacioppo, JT. \& Cacioppo, S. (2014). Older adults reporting social isolation or loneliness show poorer cognitive function 4 years later. Evidence-Based Nursing, 17(2), 59-60.

Cacioppo, JT. \& Cacioppo, S. (2018). The growing problem of loneliness. Lancet, 391(10119), 426.

Centers for Disease Control and Prevention. (2020). Older Adults at greater risk of requiring hospitalization or dying if diagnosed with COVID-19. Retrieved from https://www.cdc.gov/coronavirus/2019-ncov/need-extra-precautions/older-adults.html

Centre for Ageing Better. (2020). How has COVID-19 changed the landscape of digital inclusion? Retrieved from https://www.ageing-better.org.uk/sites/default/files/202008/landscape-covid-19-digital.pdf.

Hodge, H., Carson, D., Carson, D., Newman, L., and Garrett, J. (2017). Using Internet technologies in rural communities to access services: the views of older people and service providers. J. Rural Stud, 54, 469-478. DOI: 10.1016/j.jrurstud.2016.06.016

Martínez-Alcalá et al. (2018). Digital Inclusion in Older Adults: A Comparison Between Face-to-Face and Blended Digital Literacy Workshops. Front. ICT, 28 August 2018. DOI: https://doi.org/10.3389/fict.2018.00021

National Institute of Ageing. (2019). Social isolation, loneliness in older people pose health risks. United States Department of Health \& Human Services. Retrieved from https://www.nia.nih.gov/news/social-isolation-loneliness-older-people-pose-healthrisks.

The Survey of Health, Ageing and Retirement in Europe. (2021). [SHARE] Retrieved from share-project.org.

Seifert, A, Cotten, S.R., and Xie, B. A. (2020). Double Burden of Exclusion? Digital and Social Exclusion of Older Adults in Times of COVID-19. Journals of Gerontology: Social Sciences cite as: J Gerontol B Psychol Sci Soc Sci, Vol. XX, No. XX, 1-5. DOI:10.1093/geronb/gbaa098 Advance Access publication July 16, 2020.

Tam, M. (2018). Lifelong learning for older adults: culture and confucianism, in The Palgrave International Handbook on Adult and Lifelong Education and Learning. London: Palgrave Macmillan, 857-878. 